\title{
Application of the balancing holes on the turbine stage discs with higher root reaction
}

\author{
Lukáš Mrózek $^{1,2, a}$, Ladislav Tajč ${ }^{2,1}$, Michal Hoznedl ${ }^{1,2}$ and Martin Miczán ${ }^{3,1}$ \\ ${ }^{1}$ Doosan Škoda Power, Experimental Research of Flow, Tylova 1/57 Pilsen 301 28, Czech Republic \\ ${ }^{2}$ Univerzity of West Bohemia, Department of Power System Engineering, Univerzitní 22 Pilsen 306 14, Czech Republic \\ ${ }^{3}$ Czech Technical University in Prague, Department of Fluid Dynamics and Thermodynamics, Technická 4, Prague 6, Czech Republic
}

\begin{abstract}
The influence of the flow area of balancing holes in the discs of a steam turbine on its thermodynamic efficiency is examined for turbine stages operating in the increased root reaction regime. The interstage seal flooding with steam is modelled. The impact is given on stage reaction changes, on mass flow adjustments, and on overpressure operating in the rotor disc.
\end{abstract}

\section{Introduction}

The balancing holes on the discs are used at the turbine stages of the impulse pressure type. The holes enable minimization of the differences between the pressures on both sides of the disc and thus keeping the axial force acting on the rotor at the acceptable level. With the onset stages with the higher root reaction a question arises whether it is still acceptable to use the balancing holes of the original arrangement in the given number and diameter, or if it is necessary to modify suitably their flow area considering the root reaction of the stages and the amount of the steam leaked through shaft seal. It is also desirable to assess the possible leakage of the steam from the blade space to the balancing holes and to evaluate the impact on the performance deterioration. Therefore, the efficiency of the stage with the root reaction at a $13 \%$ - stage and with three different areas of the balancing holes was tested on the experimental turbine. The original arrangement with fully closed holes was considered as well as the arrangement with half the diameter of the holes and the variant with fully open holes. At the same time the influence of the seal steam on the change of the root and the velocity data, at the original level. Reaction was tested. Since the mass flow through the shaft seal is in comparison with the main flow insignificant, the decrease of the efficiency is caused mainly by the leakage of the steam through the balancing holes. The quantity of the leaked steam cannot be defined by using experiments. Thus, it is impossible to evaluate the quantity of the steam leaked through the nozzle blade cascade. In order to enable to compare the results from individual experiments there is the effort to keep all key aerodynamic parameters such as the input pressure and the steam temperature, as well as the pressure ratio at the stage.

\footnotetext{
${ }^{\mathrm{a}}$ Corresponding author: lukas.mrozek@doosan.com
}

\section{Stage implementation}

Basic geometrical and operational parameters of the tested stage are given in table 1. Blades adjustment and profiles implementation is evident from figure 1 .

Table 1. Geometrical and operational parameters of the tested stage

\begin{tabular}{|l|c|c|}
\hline \multicolumn{1}{|c|}{ Stage } & VT 5 & Units \\
\hline Chord & 120 & $\mathrm{~mm}$ \\
\hline Aspect ratio & 0.528 & - \\
\hline Tip seal clearance & 0.4 & $\mathrm{~mm}$ \\
\hline Pitch to chord ratio & 0.99 & - \\
\hline Root diameter & 930 & $\mathrm{~mm}$ \\
\hline Velocity ratio u/c & 0.48 & - \\
\hline RPM & 3611 & $1 / \mathrm{min}$ \\
\hline Inlet temperature & 152.6 & ${ }^{\circ} \mathrm{C}$ \\
\hline Inlet pressure & 0.775 & bar \\
\hline Pressure ratio & 0.697 & - \\
\hline Root reaction & 0.15 & - \\
\hline
\end{tabular}

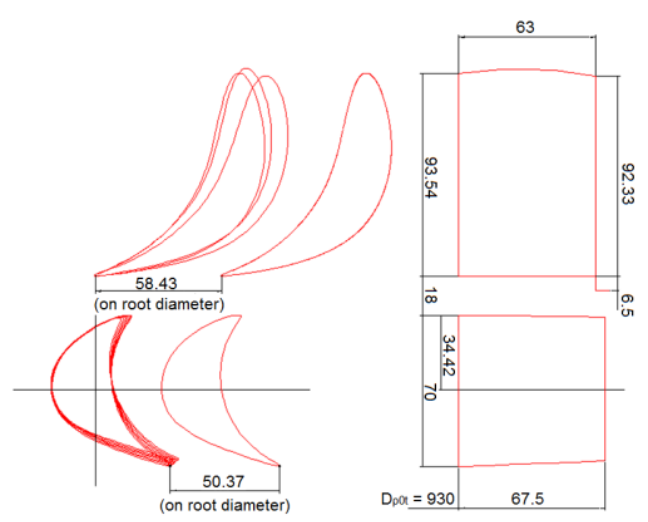

Figure 1. Tested stage blades 
Variant A

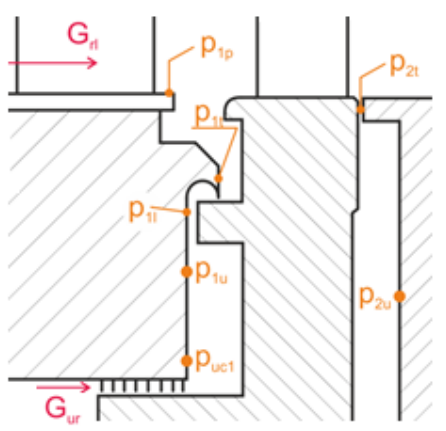

Without holes

Holes area $\mathrm{A}_{0}=0$
Variant B

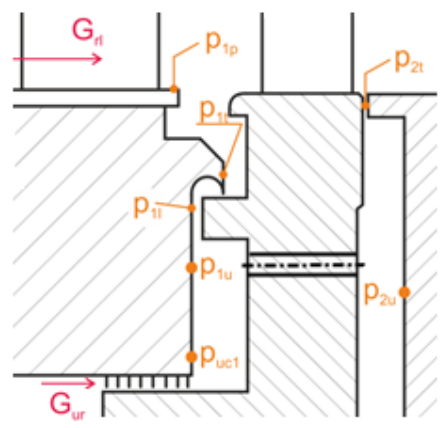

Diameter of the holes $50 \%$ Holes area $\mathrm{A}=\mathrm{A}_{0} / 4$
Variant C

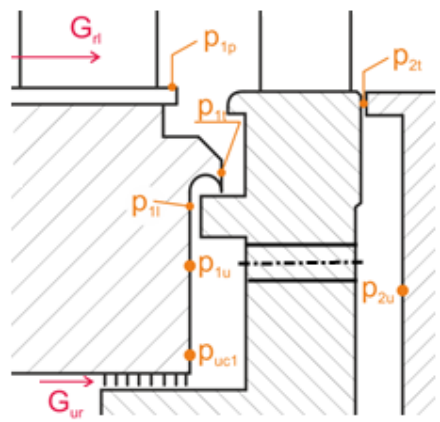

Holes open $100 \%$

Holes area $A_{0}$
Figure 2. Variants of balancing holes

The stage is, for the experiment purposes, made in the $1.27: 1$ scale. This corresponds with rotation speed $\mathrm{n}=36001 / \mathrm{min}$ and root diameter $\mathrm{D}_{\mathrm{p}}=0.93 \mathrm{~m}$. It is a stage of HP turbine part with designed root reaction $\rho_{\mathrm{p}}=0.15$.

Implementations of individual variants of balancing holes are shown in figure 2. The openings are placed under the knife-edge seal. It should limit possible steam leak from the blades to the holes. In the picture places are marked for pressure measurements and mass flows through stator blade $\mathrm{G}_{\mathrm{rl}}$ and interstage seal $\mathrm{G}_{\mathrm{ur}}$. Variant $A$ is without holes. In variant $B$ half diameter $d=20 \mathrm{~mm}$ is used and in variant $\mathrm{C}$ the openings have the original dimension, i.e. $\mathrm{d}=40 \mathrm{~mm}$.

Marking of all measured and calculated data in the observed stage is depicted in figure 3 . Using controlled steam suction $G_{x 1}$ it is possible to adjust the chamber pressure $\mathrm{p}_{\mathrm{uc} 0}$ and thus the influence the mass flow through the interstage seal $\mathrm{G}_{\mathrm{ur}}$. The experimental turbine is designed above all to define the thermodynamical efficiency, i.e. for operations with minimal influence of the interstage seal steam. In common stage tests the mass flow is $\mathrm{G}_{\mathrm{ur}}=0$ and balancing holes are covered. Turbine arrangement enables flooding and suction of steam from the interstage steal, but only in a very limit scope.

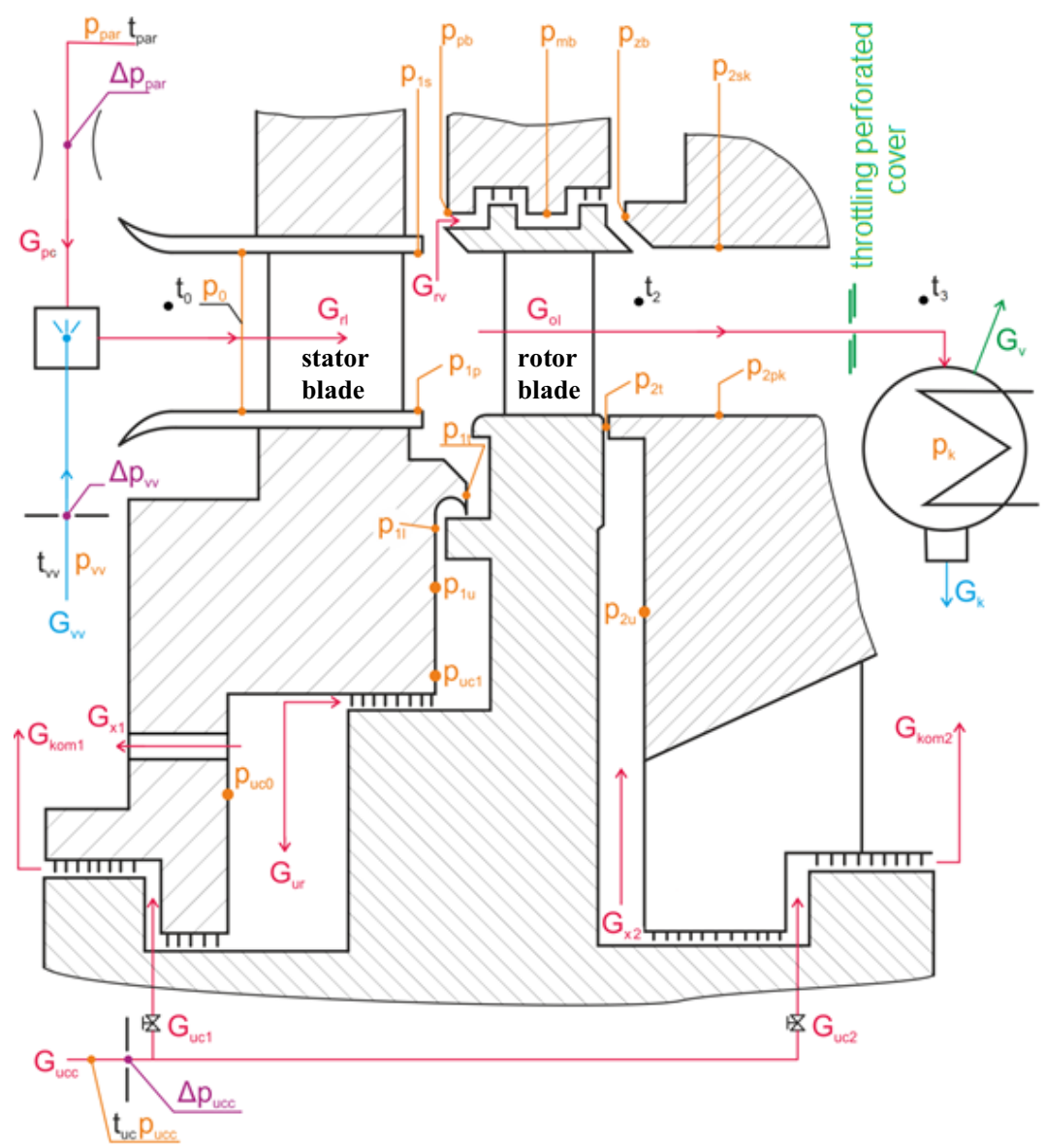

Figure 3. Scheme of measured parameters on the tested stage 


\section{Findings from experiment}

The course of temperatures and pressures on the stage in relation to the velocity ratio $\mathrm{u} / \mathrm{c}$ is given in figure 4 and 5 . The pressure drop on stage is permanent for all variants of balancing holes adjustments with $\varepsilon=0.697$. The Mach and Reynolds numbers on stage are kept at the same level.

In figure 4 steam temperatures are given before and behind the stage with the covered holes variant. Temperature $t_{2}$ is measured immediately behind the rotor blade. Temperature $t_{3}$ is recorded in the output casing near the regulator sieve above the condenser.

Temperature

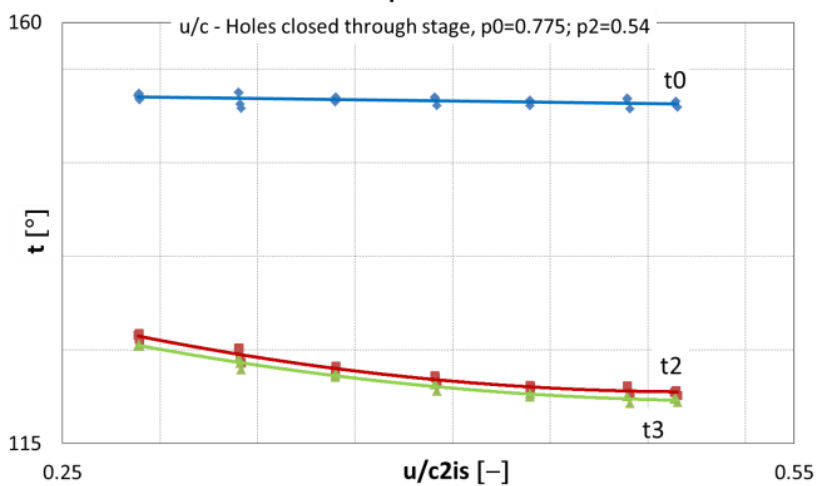

Figure 4. Steam temperature on the stage

The mean values on the stage are dependent on the velocity ratio $\mathrm{u} / \mathrm{c}$ is given in figure 5. Dividing pressure $\mathrm{p}_{1 \text { mean }}$ is already influenced by the stage reaction course and also by the size of the balancing holes area. The mass flow through the stator blades is related to the pressure change $\mathrm{p}_{1 \text { mean }}$.

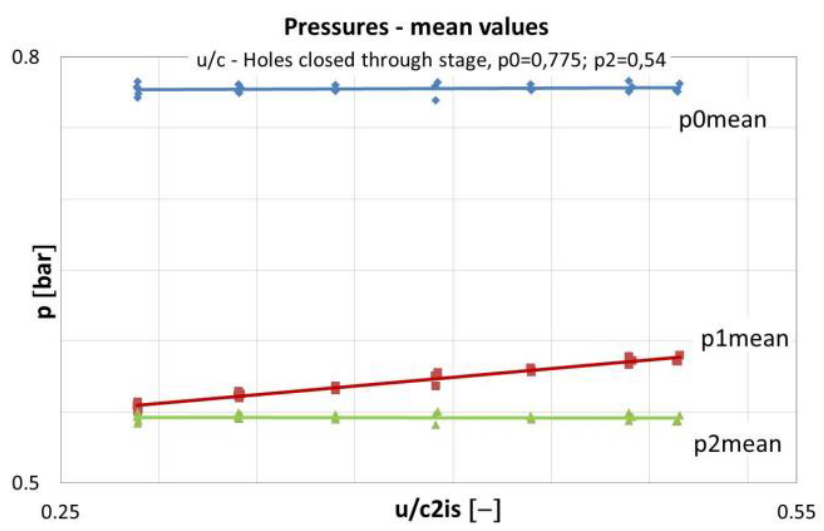

Figure 5. Pressures on stage

The mass flow through the stator blades is recorded in figure 6 . With the increase of velocity ratio $\mathrm{u} / \mathrm{c}$, under the influence of increasing pressure $p_{1 \text { mean }}$, mass flow $G_{r l}$ is decreasing. For variant $\mathrm{A}$ it is possible to calculate the steam flow through the seals and thus the mass flow through the rotor blades $\mathrm{G}_{\mathrm{ol}}$. As it is impossible from the experiments to define the steam leak through the uncovered balancing holes, the steam flow through the rotor blades cannot be calculated.

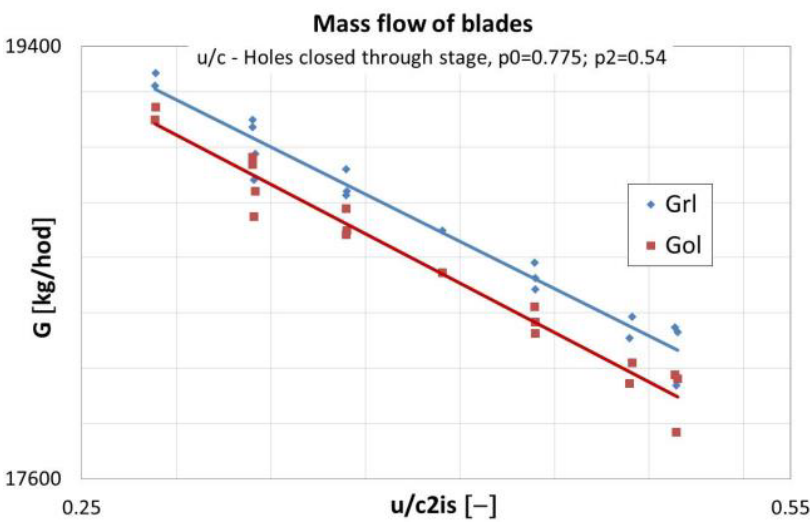

Figure 6. Steam mass flow through the stage

The scope of steam leak through the rotor seal and controlled steam flow through the interstage seal is shown in figure 7. Technical arrangement of the experimental turbine does not allow to change the steam flow in interstage seal in the scope higher than $\pm \mathrm{G}_{\mathrm{ur}}=40 \mathrm{~kg} /$ hour. This corresponds with proportional flow $\mathrm{G}_{\mathrm{ur}} / \mathrm{G}_{\mathrm{ul}} \approx \pm 0.002$. It is less than in the real implementation of the turbine stage, where the flow through the interstage seal could be comparable with the steam leak in the rotor seal.

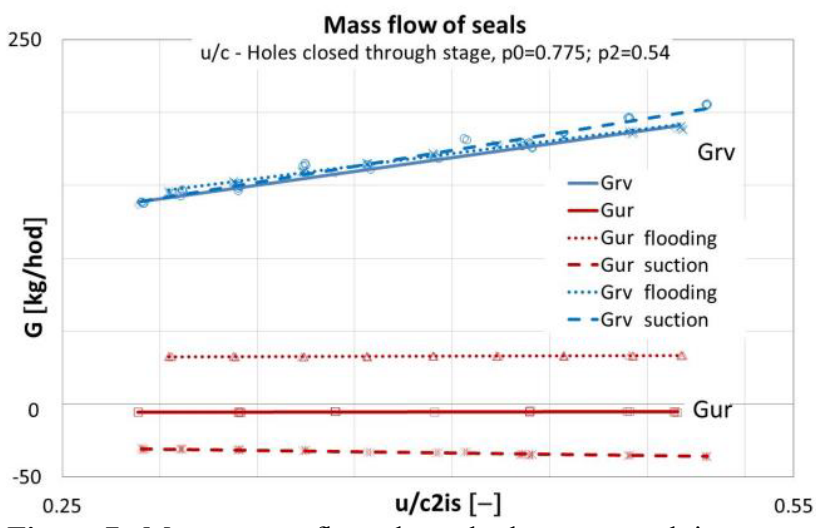

Figure 7. Mass steam flow through the rotor and interstage seals.

Comparison of proportional steam flows through both seals can be found in figure 8 .

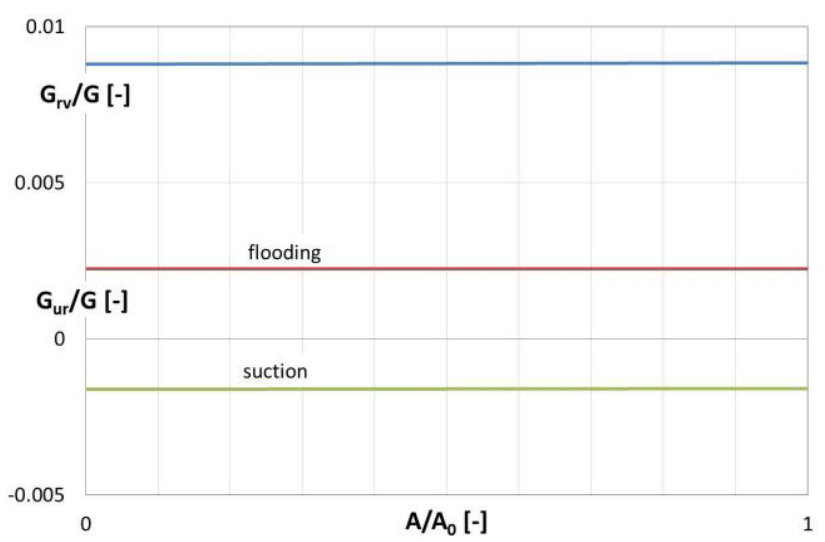

Figure 8. Proportional steam flows on seals.

It is evident that a relatively small steam leak from the interstage seal won't have a major impact on the change of root reaction or on efficiency. Possible changes of their 
values rather may be related to disc openings and the steam leak from the blade area. The effect of interstage seal steam flow adjustment on the reaction course in variant $\mathrm{A}$ is shown in figure 9. The dispersion of values on the root and tip of the stage is in both cases insignificant.

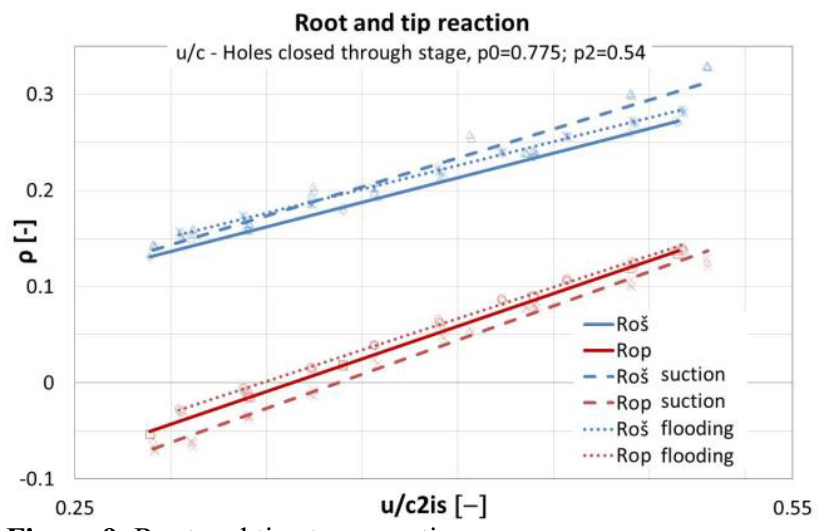

Figure 9. Root and tip stage reaction

Figure 10 shows how the root reaction changes are dependent on the amount the balancing holes are uncovered. Uncovering the holes causes drop in root reaction by as much as $4 \%$.

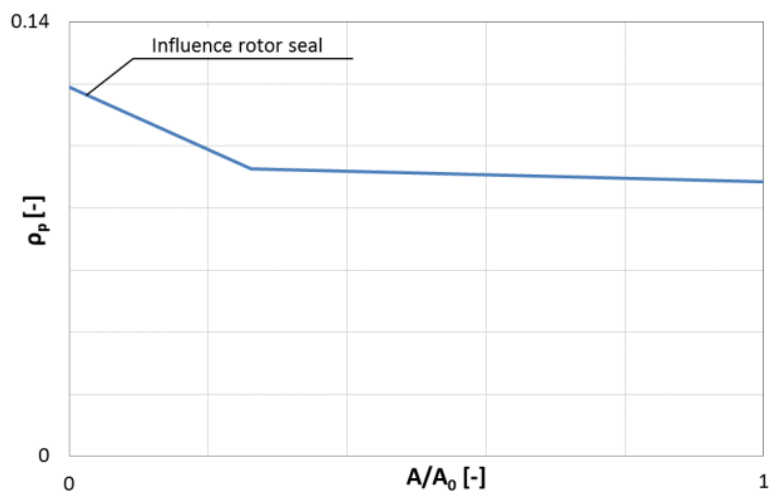

Figure 10. The influence of balancing holes area on the root reaction change for $\mathrm{u} / \mathrm{c}_{2 \mathrm{is}}=0.49$

Figure 11 shows how the steam flow through the interstage seal influences the thermodynamic efficiency of the stage.

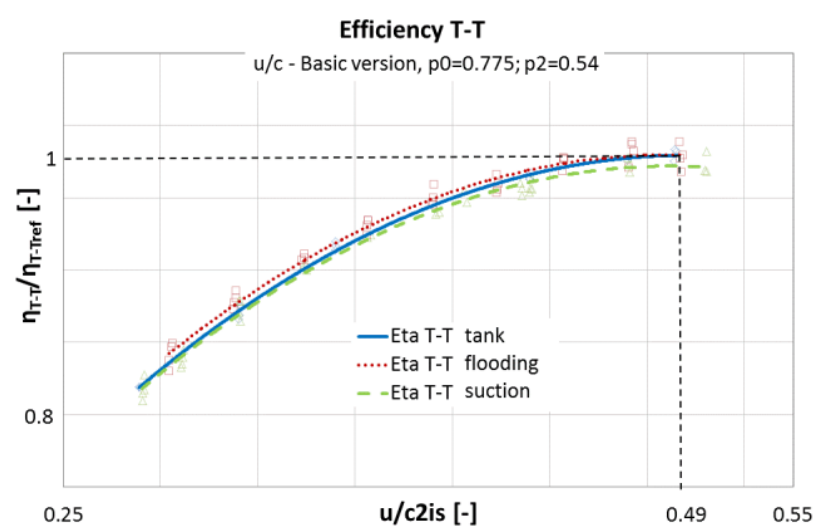

Figure 11. Turbine stage efficiency

Interstage seal flooding does not have any effect on change in efficiency. The decrease in efficiency occurs only while there is suction of steam. This phenomenon does not occur in common turbine stages. Efficiency can be calculated using temperatures measured before and behind the stage. This calculation of efficiency for variant $\mathrm{A}$ is shown in figure. 12 .

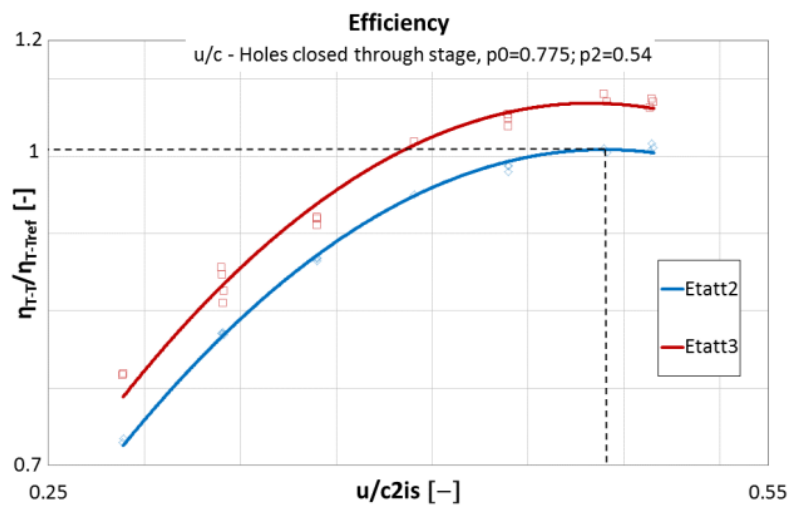

Figure 12. Stage efficiency calculated from temperatures

It is obvious that efficiency calculated from temperature $t_{3}$ is better than efficiency from temperature measured directly behind the rotor blades. Temperature $t_{3}$ can be influenced by heat transfer to the turbine body and to the condenser. Efficiency from temperature $t_{2}$ corresponds with efficiency defined using torque-meter.

Influence of covering and uncovering the balancing holes on efficiency is shown in Figure 13 and 14 . In figure 13 efficiency calculated from temperature $t_{2}$ is shown.

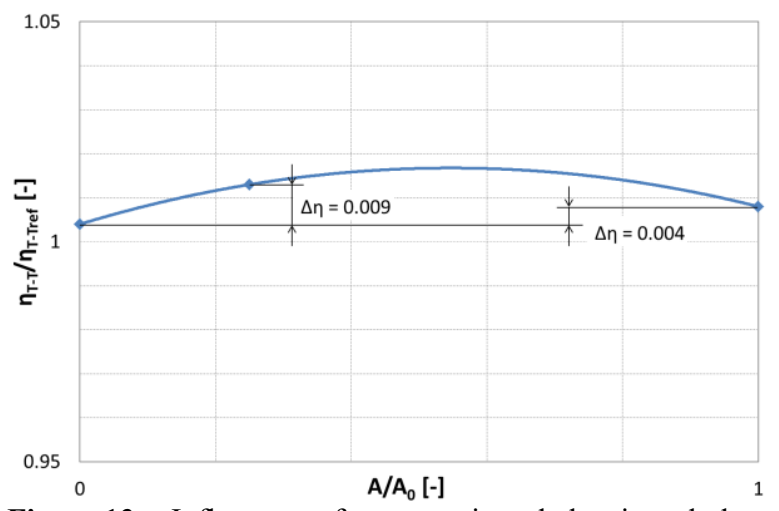

Figure 13. Influence of uncovering balancing holes on efficiency changes calculated from temperatures

Calculation of efficiency from torquemeter is shown in figure 14.

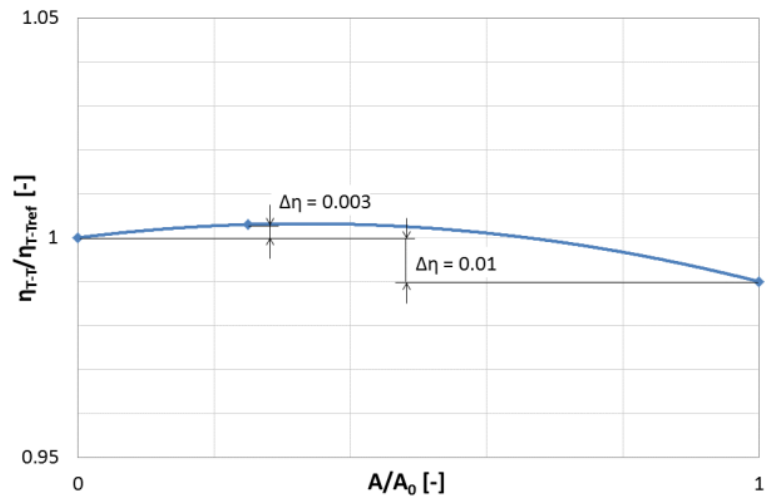

Figure 14. Influence of uncovering the balancing holes on changes in efficiency 
Partial uncovering of holes slightly increased the efficiency. But the changes do not exceed $\Delta \eta=0.5 \%$. In comparison with the covered holes variant, total hole opening reduced the efficiency by only $1 \%$. It represents only a negligible drop in efficiency. When increasing the designed root reaction to the level around $15 \%$ it is not necessary to adjust the dimensions of the balancing holes, as no distinctive steam leak from the blade area to the holes on the disc occurs. A positive effect of the sealing fin under the blade root is applied here.

Efficiency appears to be more sensitive to the Mach number level than to root reaction changes and adjustment of balancing holes. As it is evident from figure 15, with decreasing Mach number efficiency increases even by several percent. The converse effect of the loss dependent on Mach number known from experiments with blade cascades can be observed in the stage.

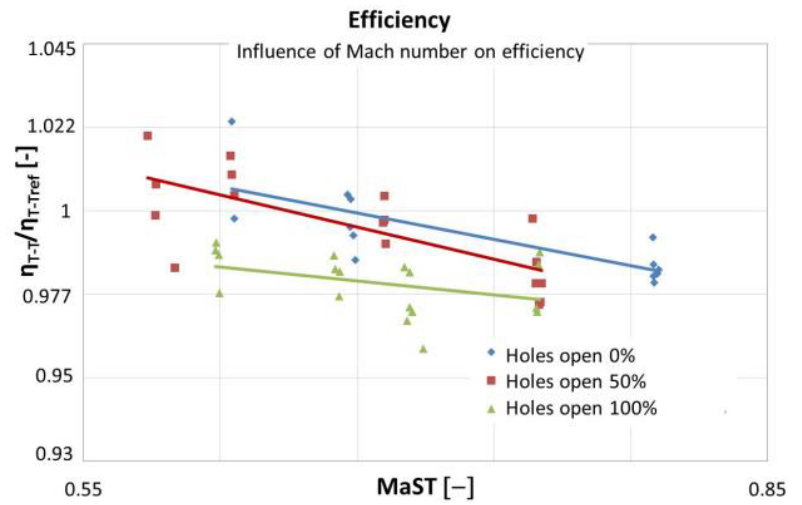

Balancing holes are supposed above all to lower the overpressure and the size of axial force influencing the rotor. It is possible to derive an estimate of the axial force from the pressure differences operating on the disc and rotor blades. The pressures before and behind the disc are recorded above and below the sealing fin and at the interstage seal level. Unfortunately while assessing the results leakage from the pressure pipes for the section around the sealing fin appeared. In figure 16 proportional pressure differences for individual variants of the experiment are calculated only from pressures on the interstage seal level and pressures at the tip and the root of the stage. Despite distorted data on pressures before and after the fin it is obvious that balancing holes perform their function and contribute to considerable drop in overpressure on the disc.

A more specific idea of pressure distribution on the disc surface can be obtained from the numerical study calculated for the stage of the same root reaction as expected in the experimentally measured stage [2]. Results of the numerical study are processed in figure 17 . Variants are considered with or without the sealing fin and also the stage with or without balancing holes. The influence of holes and the sealing fin is confirmed on the pressure distribution on the disc. Both the holes and the sealing fin contribute to lowering the axial force operating on the rotor. Placing the fin nearer to the root radius of the stage can lower the final axial force even more.

Figure 15. Influence of Mach number on efficiency
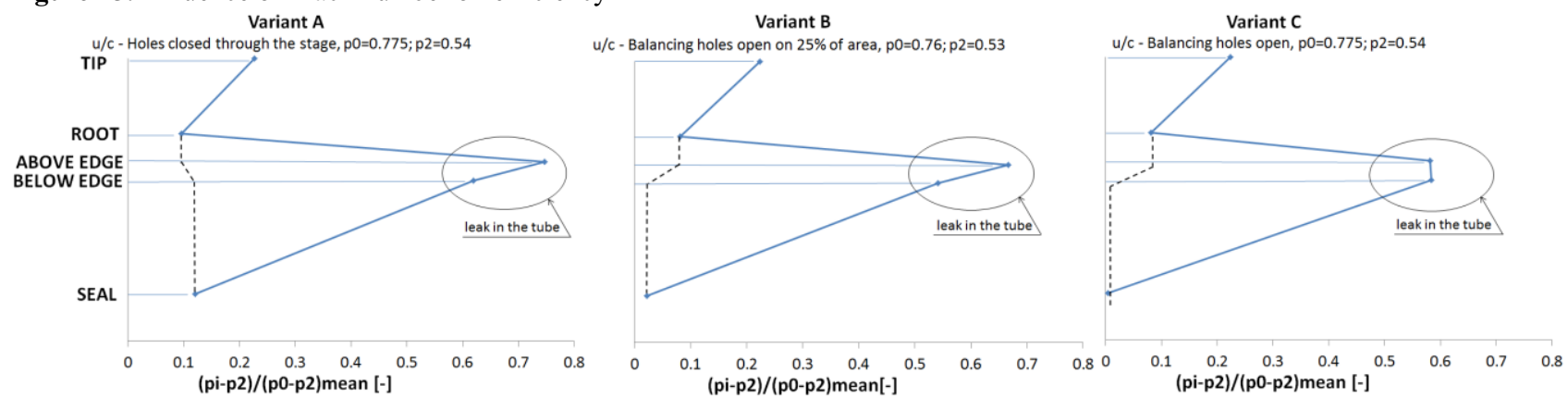

Figure 16. Pressure ratios in operational parameters

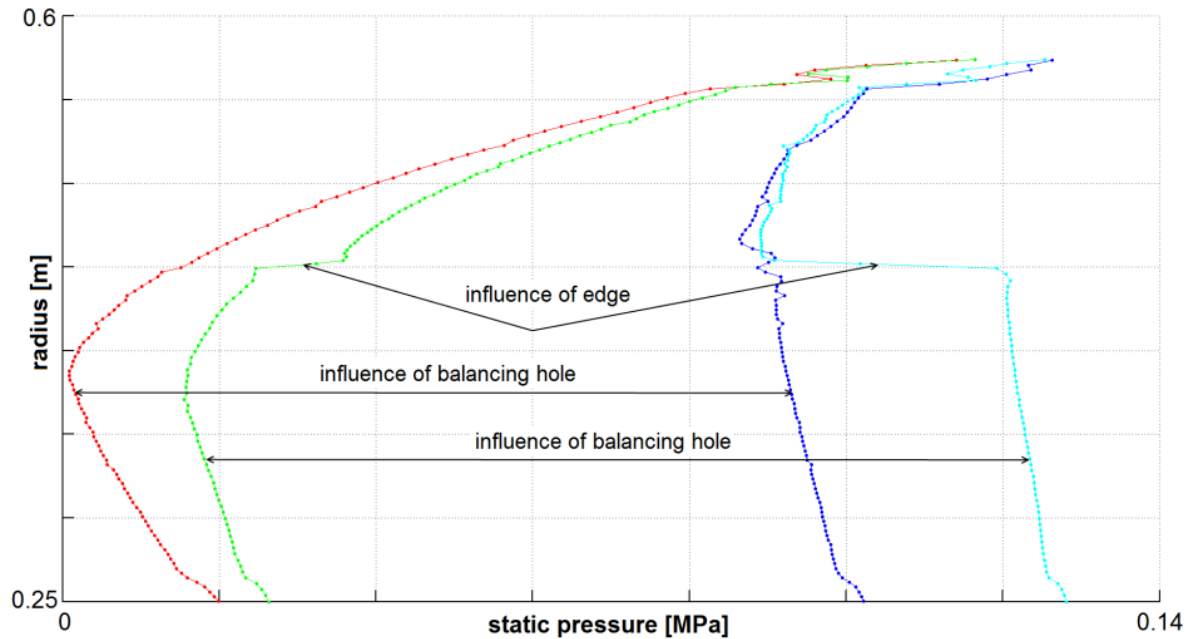

Figure 17. Numerical study of overpressure on disc with and without holes 


\section{Conclusions}

- In stages with increased root reaction $\rho_{\mathrm{p}} \approx 0.15$ for standard version with disc wheels it is not necessary to adjust the amount or size of balancing holes.

- Using the holes does not have crucial influence on the efficiency drop, but a drop in root reaction occurs.

- The size of the holes does not need adjustment for the amount of steam leak through the interstage seal.

- The influence of Mach number in the subsonic flow area on efficiency is confirmed.

- Holes in the disc contribute to lowering axial force operating on the rotor. Application of sealing fin is necessary. Also proper placing of the sealing fin is important.

\section{References}

1. L. Tajč, M. Hoznedl, L. Bednáŕ, L. Mrózek: Turbine Stage HP5 - Stage with Higher Root Reaction (Turbínový stupeň VT5 - stupeň se zvýšenou reakcí na patě), Výzkumná zpráva Doosan Škoda Power, VZTP 1087, 2015

2. V. Sláma: Numerical study Lovisa VTZ - Force Effects and the Pressure Distribution on the Rotor Disc (Výpočtový studie Lovisa VTZ - působení sil a rozložení tlaků na disku oběžného kola), Doosan Škoda Power, 2013 